\title{
Research on Income Distribution and Economic Growth
}

\author{
Xiaoli Yang ${ }^{1}$ \\ ${ }^{1}$ Guizhou University of Finance and Economics, Guiyang, Guizhou, 550025
}

KEYWORDS: Income Distribution, Economic Growth

\begin{abstract}
Income distribution and economic growth has been the focus of research in economics, is one of the largest and most complex problem areas exist, it has not formed a mature convincing research results. Especially in the case of transition of some special factors continue to produce new effects on income distribution and it lags behind the reality of the changes of the overall allocation theory. Therefore, the combination of China's real economic growth on income distribution system analysis is urgent and necessary.
\end{abstract}

\section{Introduction}

Income distribution and economic growth has been the core issue in the study of economics is economics discipline throughout the entire history of the most important theoretical and practical issues. Through the full use of scarce resources and effective configurations to maximize the promotion of human welfare, is the purpose of economic activity, but also the purpose of economic research. Basic economic activities of any society can be summarized interactive process creation and distribution of wealth, and how wealth is created and distribution and it is an important symbol of social progress in the level or degree. Moreover, one of the important issues in view of its obvious practical and policy-oriented, economic growth and income distribution is also of concern to governments.

Since the ambiguity and complexity of the interactions define the concept of income distribution and economic growth has been in the field of economics it is to study the most contentious issue. In ensuring economic growth, how the distribution of benefits and how to allocate more to promote economic growth, economists become the most discussed issue is one of the important research topics facing the theory of economic development, but also the focus of economists dispute.

In China, with rapid economic growth, income distribution gap and aggravate consequential accumulation, and become a prominent problem affecting social stability and economic growth in China. China National Bureau of Statistics survey in June 2007 showed that China's population accounts for $10 \%$ of the wealthiest population holds $45 \%$ of the national wealth, while the poorest of the population accounted for $10 \%$ of the country has only 1.4 percent of the wealth. ${ }^{1} 2005$ China's urban and rural residents per capita income ratio of 3.22: $1,{ }^{\circ}$ actual income gap between urban and rural residents far more than 3 times, the coefficient of income gap has exceeded the international warning line of 0.4. Income distribution as an important part of social production, not only the result of differences in distribution of production conditions, production conditions and is assigned a new reproduction of the source of the differences. The income gap is too large a number become a source of social contradictions and problems, we must be concerned about. However, the degree of income disparity in how to determine that the income distribution gap exactly how much is appropriate, there are no standards, what the ultimate cause of the distribution of income is, what changes in trends in income distribution gap for the future is to continue to expand and in some conditions appear next turning point, whether the income distribution helps to improve human life 
and other issues, the economy is not sufficient understanding of scholars, opinion showed great differences. Point to meet the optimal combination of economic efficiency and equal distribution of conditions, has not been able to find, it also gives the income distribution problem left a great theoretical space.

\section{The Definition of Economic Growth}

Modern economic theory, economic growth is a country or region during a given period, gross domestic product (GDP) or gross national product (GNP) and other aggregates characterized, including products and services, including output continued to increase. The former used to describe the expansion of the total production capacity of a country or region, which is used to illustrate the population growth after deducting production level of a country or region mention innings.

Thus, it can be said that economic growth especially more output and higher efficiency is put more or to get more output. Its essence is a description of the production function of the relationship between growth and output growth. At the micro level, the production function is the corporate capital or labor inputs and other factors increase a certain amount, how much production will increase. At the level of a country or the whole economy, the production function refers to the relationship between a country's labor force, capital stock and gross national product of the country between the levels. Therefore, we can use the aggregate production function to explain or illustrate a country or region in the capital stock and labor input growth in the case of a certain number of output growth in GNP.

\section{Related Research on Income Distribution}

In modern development economics, income distribution is usually divided into functional income distribution (Note: also known as "factors of production according to the share of income distribution") and the scale of the income distribution of two types. Functional income distribution, also known as factor income distribution, is to land, capital and labor and other factors of production as the mainstay, according to the role of the factors of production play in social production or contribution made, the distribution of the national income. Income distribution study of functional analysis mainly lies in the relationship between the various elements of the production and its contribution to income between is reasonable. Income distribution scale, also known as personal distribution of income or household income distribution is allocated separately to individual residents or families subject to income carried out. Scale study is to analyze the relationship between income distributions is mainly a revenue share class stratum of the population or the proportion of family income between its reasonableness.

It emphasizes the sources of income and it helps to reveal the distribution of elements of the relationship between the owners. Due to practical reasons, attention to functional distribution theory far more than income distribution scale.

Income distribution scale is a resident individual (or family) conducted national income as the main distribution. For example, per capita income level of the family of all sorts, analysis of different proportion of household income. It simply involves the individual (or family) and all income earned, and access to income through not considered. It is concerned with how much personal income, regardless of whether those revenues solely from the occupation or also from other sources, such as profit, interest, rent, gift or inheritance. 


\section{Related Research on Income Distribution and Economic Growth}

Economic growth and income distribution are closely linked, is a dynamic interaction and mutual influence of the relationship between the two, leaving economic growth and the distribution of income or only a single study to consider the promotion of economic growth without regard to income distribution, in It has a certain one-sidedness of the research methods. In particular Judgment whether income distribution gap is too big, the gap allocation is reasonable, the main basis to see if there is one conducive to economic growth.

Economic growth and income distribution relationship is the development of research topics of economics. To date, the western economic circle of the relationship between income disparity and economic growth has been 50 years of intensive research. Academic researches mainly around two aspects: First, the study of long-term trends in economic growth or changes in the economic development process of income distribution; second is the impact of changes in income distribution on economic development and economic growth. The former is mainly around the so-called Kuznets inverted $U$ curve can be set up and expand, which focuses on the distribution of income inequality if there is conducive to economic growth and income distribution which is more conducive to economic growth. Many scholars have recognized, in fact, two-way relationship of mutual influence between economic growth and income distribution, rather than a one-way relationship.

In the 20th century, 90 years, regardless of the model specification research models and empirical analysis, the discussions have focused on the impact of income distribution on economic growth in. The majority consensus is that unequal distribution of income and so not have a direct impact on economic growth, but indirectly through the direct factors that affect economic growth) capital, labor and technology on economic growth act, or can be said that by influencing investment and demand affect the final economic growth.

Contemporary literature study income distribution, most of the research is how economic growth affect income distribution, and large changes in the economic development of the economic structure, technological change and macroeconomic fluctuations, analyzes the impact of economic growth and human capital accumulation of material, thus affecting the formation of the income distribution differences.

Most economists agree with the decisive role of economic growth on income distribution, but there are some scholars believe that the change in the distribution of income is the result of many factors, including the representative of Adelman and Morris. Their research showed that just 6 per capita GNP can explain the changes in income distribution an important factor is good, and not the most important factor. In this regard, although the changes in income distribution is the result of the interaction of many factors, but these factors and economic growth are closely linked, who supported the development model study part their understanding.

Recent World Bank research report that economic growth plays a decisive impact in reducing poverty, but its effect is very different in different countries. At the same time, economic growth in reducing income gaps showed no significant effects. In contrast, the income gap is too large it will certainly lead to frequent social conflicts directly affect economic growth. So for the elimination of poverty and reduce the income gap is too large, the economic growth is a necessary, but economic growth alone is not enough.

Income Distribution Effects of economic growth, the existing literature, mainly along two clues: First, income distribution affects economic growth from the demand side; the second is the income distribution affects economic growth from the supply side. Lack of effective demand Keynes explained the income distribution impact of consumer demand, thus affecting economic growth. 
Focus on the impact on economic growth, income distribution about the origin of the study of the new Cambridge school. Cambridge School theory of income distribution is the biggest characteristic of the relations of distribution for dynamic analysis, the theory of income distribution and economic growth theory together, and relations affect mainly from income distribution on capital formation, income distribution and economic growth are analyzed in income allocated out of the pure product pricing and income distribution is divided into categories.

In the history of economics, different viewpoints study the impact of income distribution on economic growth can draw different conclusions. Traditional mainstream economics, the study of the relationship between growth and distribution from the perspective that the total supply of labor surplus and shortage of capital is the economic growth of developing countries in the process of common problems, unfair distribution of income, social wealth to the hands of a few concentrated, conducive to the increase in savings and investment growth, promote economic growth. In Sismondi represented by faction economist at the perspective of the relationship between aggregate demand and growth allocation from the view that the degree of expansion of income inequality will reduce consumption and investment propensity is not conducive to increasing consumer demand and thus hinder the effective demand Economic Growth.

Analysis of the distribution of income and unequal income distribution at any time can not leave the economic growth itself were contrary analysis of income distribution must start from economic growth, to promote economic growth if efficiency is determined based on the reality of income distribution pattern and inequality Degree. So, from the methodology that the study of income distribution actually still has to return to the neoclassical school opened "Assign a growth" analytical framework and track.

In general sense, economic growth, income distribution is always the basis and conditions. Economic growth caused by changes in the distribution of income on their results, there are two, one is accompanied by economic growth caused by the gradual improvement of income distribution, including the eradication of poverty and the unemployed and to reduce inequalities that people in absolute and relative income inequality income inequality has improved. Second, with economic growth lead to worsening income distribution, namely, poverty population growth and widening wealth gap, income distribution differentiation or polarization. In the process of economic growth, income distribution whether it is improving or deteriorating gradually, not by peoples' subjective will and aspirations of the decision, but by the total economic growth rate and the different stages of growth and growth of institutional conditions, the policy orientation decided.

\section{Conclusion}

Economic growth and the distribution of income subject to different economic conditions and the economy, and thus exhibit different characteristics. However, rapid economic growth in the moderate and rational income distribution is possible and conducive to economic growth. The income gap will not automatically shrink as the economy grows, the market gap narrowing is powerless, to adjust the size of the gap between the needs of the government through appropriate policies and institutions to carry out.

\section{Reference:}

[1] Lin et al.'s Relations among economic development strategy and equity, efficiency [J]. Economics (quarterly), 2003 (2).

[2] Zhao Liang West. Summary of Income Inequality and Economic Growth Study [J]. Economic 
Perspectives, 2003, (8).

[3] Gao Fan latest dual economic structure theory research progress [J]. Economic Perspectives, 2003 (9).

Economic Growth and Income Distribution Relationship between theoretical views comments [4] Liu Li. [J]. Guangzhou University of Foreign Studies, 2010.

[5] Zhang Weiying. Credibility based legal system [J]. Economic Research, 2002 (1) 